\title{
Migration's inability to alleviate regional disparities: the grass is still greener on the other side of the fence
}

\section{Lorenz Benedikt Fischer $^{1}$ (iD}

Published online: 6 July 2018

(c) The Author(s) 2018

\begin{abstract}
This paper attempts to explain the seeming unresponsiveness of labor to react to economic disparities in terms of migration. In theory, the potential of workers to implicitly alleviate regional disparities in, for example, unemployment or wage levels by relocating appears potent, but finds little support empirically. To resolve this perplexity, a dynamic discrete choice model is used, which translates into a two stage estimation strategy for recovering structural parameters. Investigating Austrian bilateral movements on the NUTS 3 level from 2002 to 2014, the results suggest that this unresponsiveness builds on two pillars. First, estimated average migration costs are in the range of six times the average annual wage, which appears sizable enough to prevent taking advantage of economic opportunities for workers. These costs are shown to have decreased over time, though. Second, the relatively high variation in the random utility shifter can be interpreted as relative unimportance of regional disparities in forming migration decisions. Finally, a spatial approach on estimated regional valuations reveals an apparent 'beauty contest' of regions, where regions' own valuations suffer from proximity to highly attractive ones.
\end{abstract}

Keywords Regional migration · Dynamic discrete choice $\cdot$ Gravity $\cdot$ Migration costs $\cdot$ Regional disparities

JEL Classification $\mathrm{R} 10 \cdot \mathrm{R} 23 \cdot \mathrm{C} 31 \cdot \mathrm{C} 35 \cdot \mathrm{D} 15$

\section{Introduction}

Labor mobility presumably has great potential in alleviating differentials across countries, regions, or even sectors. From early classical trade theory on, where equalized factor prices follow from factors moving to the location with the highest

Lorenz Benedikt Fischer

Lorenz_Benedikt.Fischer@jku.at

1 Department of Economics, Johannes Kepler University Linz, Altenberger Strasse 69, Linz, Austria 


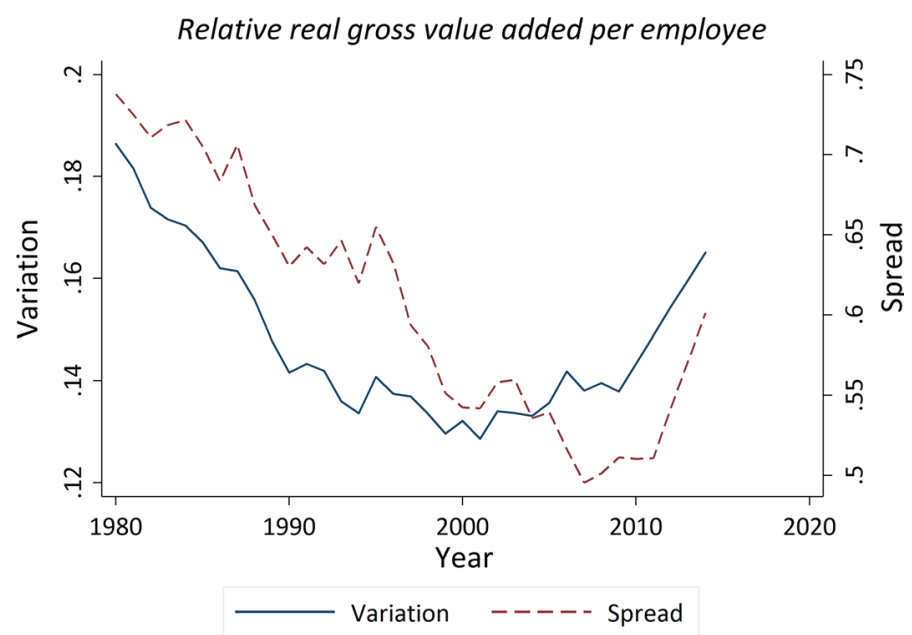

Fig. 1 Variation (SD) and the spread (maximum-minimum) of real relative-yearwise-GVA per employee in Austrian NUTS 3 regions

marginal product (Samuelson 1948), the literature has created numerous strands on the possibility of migration's ability to do so. Prominent examples which are still under investigation are differentials in wages levels, country and/or sector-wise, unemployment rates, or income per capita growth. Conclusions are ambiguous, depending on the data, theoretical foundation, and also econometric methods. Geographically, until some 30 years ago, research concentrated mainly on country-level data, perhaps mostly due to limited data availability and interest of policy makers. However, this interest also moved towards sub-national levels, probably for the same reasons. At the latest the establishment of the European Union created the necessity of investigating these questions sub-nationally, considering far-reaching regional policy targets with around one third of the total EU budget (approximately $€ 352$ billion from 2014 to 2020) spent on cohesion policy. ${ }^{1}$

Relevant contributions dealing with the impact of migration on regional differentials are numerous. Dustmann et al. (2008) discuss the role of immigrants' skills in determining the wage effects on native skill groups. Within the same skill group, if workers are seen as substitutes independently of their origin, immigration should naturally lead to falling wages due to increased supply, and may also exert pressure on natives to leave the labor market (Borjas 2003). In extent, migration from low- to high-wage regions/countries should let wage differentials clear out (Borjas 2001). As a counterexample, consider the evolution of relative real gross value added (GVA) per employee and movements in Austrian NUTS 3 regions, which form the base for the empirical part of this paper, depicted in Figs. 1 and 2. Even though the variation in GVA per employee declined from roughly $18.5 \%$ in 1980 to about $13 \%$ in the year 2001, it has since been steadily increasing until 2014. For the spread, the

\footnotetext{
${ }^{1}$ See http://ec.europa.eu/regional_policy/en/policy/what/investment-policy/.
} 


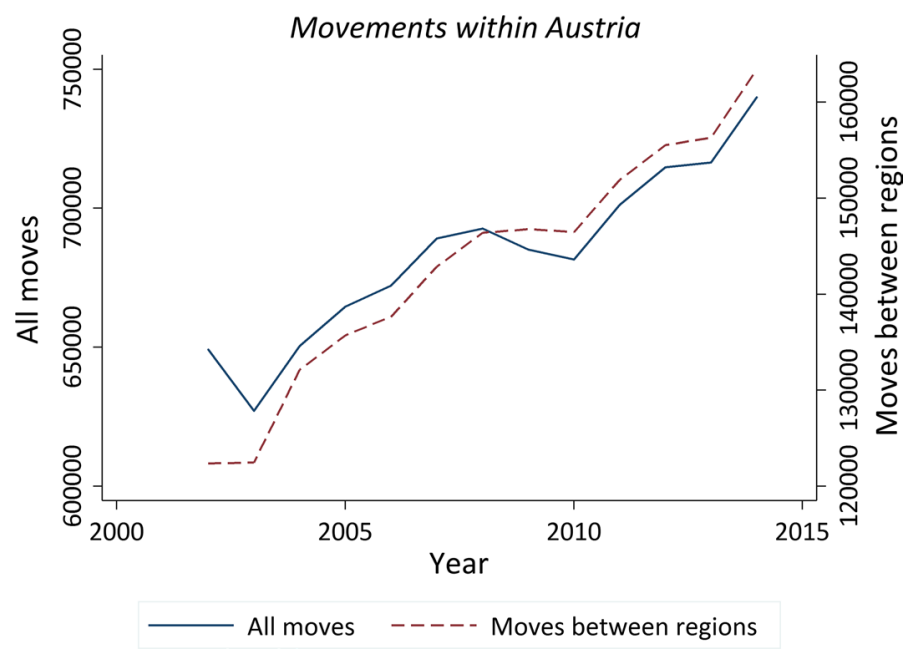

Fig. 2 Resettlements in Austrian NUTS 3 regions with and without inner-region resettlements

minimum lies in 2007, but paints a similar picture. Over the period from 2002 to 2014 , thus, the distribution of real GVA per employee has become more unequal, despite a steady increas in within-as well as between movements. ${ }^{2}$

On unemployment, Basile et al. (2012) detect a negative relationship between net-migration and unemployment rates for Italian NUTS 3 regions, a result which is also confirmed in a recent investigation that additionally accounts for human capital flows that come with migration (Basile et al. 2016). In contrast, Niebuhr et al. (2012) conclude that migration in fact reduces disparities for German NUTS 3 regions. Recently, Granato et al. (2015) find opposing effects of migration of highand lower-skilled workers in German functional labor market regions, where highskilled (lower-skilled) migration would lead to increasing (decreasing) disparities in regional unemployment rates. Still, the overall picture suggests that the impact of labor mobility on unemployment is negligible (Okkerse 2008).

On regional income growth rates, Barro and Sala-i Martin (1992) in one of the most-cited contributions on this topic, conclude that "we showed that exogenous changes in migration seem to be unimportant in explaining the process of interregional convergence' (p. 28). Fischer and Pfaffermayr (2017), though, find accelerated $\sigma$-convergence across European NUTS 2 regions through migration. Looking again at regions within particular countries, Fratesi and Riggi (2007) find that similar to unemployment, migration increases disparities regarding income per capita in Italian regions. Opposingly, Kırdar and Saracoğlu (2008) conclude that migration in fact promotes convergence.

\footnotetext{
${ }^{2}$ In total, there were $8,884,194$ moves within the same period, or $1,860,014$ excluding within-region relocations.
} 
These examples should clarify that labor mobility is a reoccurring, widely discussed, and also disputed topic. The majority of contributions also recognizes concerns of possible endogeneity of migration as explanatory factor. Contradictory conclusions may also indicate a mere unrelatedness between migratory flows and economic indicators, especially considering a possible publication bias.

Finding and defining the determinants of regional migration is a branch of literature on its own, and will be reviewed in the next section. Since it is well known that the majority of movements happens within national borders, an exploration of what makes more people take off to one particular region than to another when facing a set of possible destinations seems vital. This study attempts to raise attention towards two rather neglected questions in the discussion. First, an elicitation of regional migration costs is currently unattainable to the best of the author's knowledge. Second, this study provides support to the notion that (aggregate) regional migration flows appear detached from economic disparities.

The rest of this paper is organized as follows. In the next section, the literature on the determinants of migration will discussed, broken down into international and regional investigations. Bilateral studies predominantly follow gravity-type approaches, and therefore the focus is on that branch of the literature. Section 3 introduces a simple multi-regional dynamic discrete choice model leaning on Artuç (2013). Section 4 explains the estimation strategy and presents the case of Austrian regional migration. Sections 5 and 6 present estimation results and concluding remarks.

\section{Related literature}

In his review, Etzo (2008) recognizes that 'the gravity model is the most common theoretical framework used in empirical analysis to study the spatial determinants of migrations' (p. 19). The majority of migration research has been done on international movements and has generated a large pool of insights that may also perpetuate to regional migration. On one hand, international flows are more frequently investigated due to the immanent policy relevance, as it appears so recently. A large part of the variation of these bilateral migration patterns can be explained by relatively time-invariant institutional factors, such as language, colonial history, or a common border (Leblang et al. 2009; Ramos and Surinach 2013). These factors are all to be seen as some measures of costs of migration, may they be 'forward' in the sense of costs which emerge in the destination (such as learning a new language or tight immigration policies) or 'backward' in the sense of costs emerging by leaving the origin (such as lost networks). The contribution by Foot and Milne (1984) is among the early ones to find classical gravity-style determinants of migration, which are the distance between sending and receiving location, and the mass of either, represented by population. Typically, bilateral migration flows are hypothesized increasing in the population of either and decreasing in distance. Karemera et al. (2000), on immigration to North America, claim that the population of the sending country has the utmost explanatory power. Also the negative impact of distance is confirmed 
empirically in virtually all studies, internationally as well as regionally. Thus, stylizing migration as manifestation of gravitational force seems appealing.

Also impacts of climatic factors are investigated, though found not to directly impact international migration decisions (Beine and Parsons 2015). ${ }^{3}$ Further, McKenzie et al. (2014) find that potential foreign immigrants are more sensitive towards set minimum wages than to the general wage level. Concerning policy relevant issues Bertoli and Moraga (2013), for example, find strong externalities of immigration policies on other possible destination countries, which in theory relates to a change in relative migration costs. Accordingly, Bertoli et al. (2013) estimate migration costs to the US in the magnitude of approximately five to eight times the average domestic income for Ecuadorian immigrants.

Considering bilateral movements within national borders, above mentioned factors mostly cancel out since they are to a large part constant within the sample. On a regional level, contributions are sparse, even though it is well-known that the majority of movements in Europe is happening within a country. As Dijkstra and Gáková (2008) report, approximately 85\% of migratory flows on the NUTS 2 level in the EU are observed within a country. It is self-evident that international movements play an important role in economic dynamics, but considering the sheer size of within-country migration, analyzing its causes, costs, and consequences seems fundamental. For example, Jackman and Savouri (1992) find that migration appears responsive to regional labor market conditions, such that high unemployment leads to emigration, and a higher vacancy rate increases immigration. This result also indicates that unemployed individuals tend to search more than employed and, as a consequence, are more mobile. For Chinese provinces, Poncet (2006) states that the increased sensitivity of the population towards income and unemployment would strengthen labor market efficiency, but that this ability is impeded by high migration costs. A recent publication by Dotti et al. (2013) on relocation decisions of Italian graduates stresses the importance of labor market conditions as determinants of migration decisions. Further, Piras (2017) points out the emigration-restraining effect of regional human capital. Even though one can find some representation of migration costs and how they affect location decisions, a quantification thereof is missing. Within this study, the intention is to fill this gap. In the vein of Poncet (2006), a high level of migration costs may be the reason for the ineffectiveness of migration to alleviate regional economic differentials, or the cause of increasing differentials in the light of Granato et al. (2015), as explained above. The intuition is simple: The higher the costs to move, the higher potential benefits of moving need to be to actually induce migration, which may lead to perverted effects. Another reason may simply be that individuals are relatively unconcerned with such differences in economic opportunities, unless potential benefits were staggering. As will become clear, the approach taken here allows to infer on both arguments.

\footnotetext{
${ }^{3}$ It is found, however, that the propensity to natural disasters affects wage differentials.
} 


\section{Theory}

The structural gravity approach in economics originates from the international trade literature, and has gained exceptional importance in this field. The elegance and power of this framework follow from the ability to investigate flows between an importer and an exporter in dependence of frictions between the two actors as well as all other bilateral frictions. Anderson (2011) also makes a similar statement regarding factor mobility.

The usual starting point for developing a structural gravity model of migration is a random utility model that, for each individual $l$ in some region $i$, assigns utility $U^{i j, l}$ to migrating to region $j$. Typically, this utility is assumed log-linear and to depend on observed benefits $w^{j}$, migration costs $m^{i j}$, and some random term $\varepsilon^{i j, l}$. These benefits are mostly conceptualized as income, employment opportunities, or in combination as expected income. Migration costs, on the other side, are usually univariately explained by the distance between the origin and the destination, where the measure may be discrete or continuous. For example, Poncet (2006) uses a combination, continous distance and a neighbor-region indicator to investigate the role of distance. However, distance may also capture costs not relating to 'direct' physical costs, like cultural differences, fading networks, or other psychological costs, since these measures are presumably positively correlated.

The framework presented here follows the dynamic discrete choice set-up (and estimation strategy) by Artuç (2013), which is also employed in a follow-up contribution on sectoral and occupational mobility in the United States (Artuç and McLaren 2015). However, this approach has not been used to elicit regional or international migration patterns. To fit the available data to be explained in the next section, the model is simplified in so far as there is a single type of worker. ${ }^{4}$ Thus, workers distinguish themselves solely by their locational choice. Conceptually, this model clarifies that the estimated parameters of the 'typical' gravity equation are to be interpreted as valuations of regions.

Taking the point of view of the decision maker, the utility of a worker living in region $i$ is given by the current wage $w_{t}^{i}$, assumed constant within a region, some region-specific (unobserved) term $\eta^{i}$, and the discounted expectations about the future. Before making the decision to possibly relocate at the end of a period, all random utility draws become known to the worker, as do migration costs $m_{t}^{i j}$ for all region-pairs, where $m_{t}^{i i}$ is nil (Artuç et al. 2010). Followingly, the Bellman equation representing the utility $U_{t}^{i l}$ of worker $l$ in region $i$ writes as

$$
U_{t}^{i l}=w_{t}^{i}+\eta^{i}+\max _{j}\left[\beta \mathrm{E}_{t}\left(V_{t+1}^{j}\right)-m_{t}^{i j}+\varepsilon_{t}^{j l}\right]
$$

\footnotetext{
${ }^{4}$ In principle, this model allows for more than one type of worker. For example, a promising expansion appears the differentiation between employed and unemployed workers or singles and families, to disentangle the determinants of migration of either group. Given suitable data, such a set-up could then be extended to a general equilibrium approach in order to simulate impacts of different types of shocks on migration patterns.
} 
where $\beta \in[0,1]$ is a discount factor, $\mathrm{E}_{t}\left(V_{t+1}^{j}\right)$ represents the expected next period's value of being in some region $j$, and $m_{t}^{i j}$ are migration costs between regions $i$ and $j$. Finally, $\varepsilon_{t}^{j l}$ is a random utility shifter. In the following, the individual index $l$ is disregarded for the sake of comprehensiveness. To derive the value-function of region $i$, take the expected utility with respect to the random utility shifter:

$$
\begin{aligned}
V_{t}^{i} & =\mathrm{E}_{t}\left(U_{t}^{i}\right)=w_{t}^{i}+\eta^{i}+\mathrm{E}_{t} \max _{j}\left[\beta V_{t+1}^{j}-m_{t}^{i j}+\varepsilon_{t}^{j l}\right] \\
& =w_{t}^{i}+\eta^{i}+\beta \mathrm{E}_{t}\left(V_{t+1}^{i}\right)+\underbrace{\mathrm{E}_{t} \max _{j}\left[\bar{\varepsilon}_{t}^{i j}+\varepsilon_{t}^{j}\right]}_{\Omega_{t}^{i}}
\end{aligned}
$$

where

$$
\begin{gathered}
\bar{\varepsilon}_{t}^{i j}=\beta \mathrm{E}_{t}\left[V_{t+1}^{j}-V_{t+1}^{i}\right]-m_{t}^{i j} \\
\Omega_{t}^{i}=\sum_{j}^{N} \int_{-\infty}^{\infty}\left(\varepsilon^{j}+\bar{\varepsilon}_{t}^{i j}\right) f\left(\varepsilon^{j}\right) \prod_{k \neq j} F\left(\varepsilon^{j}+\bar{\varepsilon}_{t}^{i j}-\bar{\varepsilon}_{t}^{i k}\right) \mathrm{d} \varepsilon^{j}
\end{gathered}
$$

As in Artuç (2013), the assigned value of a particular choice is split up into three parts: the region-specific fixed utility, expectations about the future in that region, and the option value as depicted in (5). The option value states that the valuation of a region, additionally to its own appeal and low immigration costs, may increase by the ease at which a worker can move again. Geographically, this would imply that regions with a high degree of centrality in terms of lower migration costs outwards will also show higher immigration. Assuming that migration costs are partly symmetric, one should observe positive correlation between immigration and emigration flows. Mathematically, the option value is the sum of expected net gains over all possible choices weighted by the chance that one particular choice is the most preferred. $^{5}$

Conceptually, the decision maker does not only consider the state of a region itself (relative to all other options), but also the states of and the connectivity to all other regions. For example, an individual that moves to some suburb region of an economic central region may do so not only because of the utility generated by that region itself, but additionally because of the proximity to that center. In that sense, the model is able to explain housing location decisions in dependence of characteristics of the destination (for example, housing prices) as well as its surrounding regions (for example, employment opportunities). This implies that the possibility that the region of the workplace need not be the same as the region of residence is already included in the decision

$\left.\overline{{ }^{5} \text { See that } F\left(\varepsilon^{j}+\bar{\varepsilon}_{t}^{i j}-\bar{\varepsilon}_{t}^{i k}\right) \text { is equivalent to } \mathrm{P}\left(\beta \mathrm{E}_{t} V_{t+1}^{k}-m_{t}^{i k} \leq \beta \mathrm{E}_{t} V_{t+1}^{j}\right.}-m_{t}^{i j}\right)$. 
process through a region's valuation. In the same manner, one can argue that while the housing decision is geographically traceable and attributable to a region, labor markets may not be confined to the same borders. However, policy decisions are often based on regional classifications, such as the Nomenclature des unités territoriales statistiques (NUTS), for example the allocation of structural funds by the European Union. This possible migration-determining influence of neighboring regions calls for modelling housing decisions also on these characteristics. These contemplations are implicitly part of the decision process through, for example, varying job offer rates or migration costs. Neglecting possible benefits or costs which stem from characteristics of neighbouring regions may bias the impact of regional 'goods' upwards and 'bads' downwards.

The last step is utilizing McFadden (1974) and let the random utility shifter $\varepsilon$ follow a type-I extreme value distribution with mean zero and scale parameter $v$. Then, the probability $q^{i j}$ of migrating from region $i$ to region $j$ is given by the share of the exponential of the expected discounted net gain of option $j$ over the sum of all exponentiated expected net gains, each divided by the scale parameter $v$ (Artuç et al. 2010).

$$
q_{t}^{i j}=\frac{\exp \left(\bar{\varepsilon}_{t}^{i j} \frac{1}{v}\right)}{\sum_{k=1}^{N} \exp \left(\bar{\varepsilon}_{t}^{i k} \frac{1}{v}\right)}
$$

Equipped with these considerations, in the next step migration costs, the importance of wages compared to random utility shifts, and the revealed valuations of regions shall be investigated.

\section{Estimation and data}

\subsection{Estimation}

The estimation strategy too follows Artuç (2013), who proposes a two-stage approach for estimating dynamic discrete choice models resembling the one presented above. The first stage estimates gross flows as

$$
L_{t}^{i} q_{t}^{i j}=y_{t}^{i j}=\exp \left[\Lambda_{t}^{j}+\Gamma_{t}^{i}+\Psi_{t}^{i j}\right]+\xi_{t}^{1, i j}
$$

where $L_{t}^{i}$ is the current population in region $i, y_{t}^{i j}$ is the number of migrations from region $i$ to $j$ at time $t, \Lambda_{t}^{j}$ captures destination-time fixed effects, $\Gamma_{t}^{i}$ displays origintime fixed effects, and $\Psi_{t}^{i j}$ represents dyad-specific moving costs, possibly changing over time. In that sense, $\Lambda_{t}^{j}$ is the measure of the expected choice-specific utility of $j$. Rewriting Eq. (6) into the first stage estimation equation reveals the affinity towards a gravity representation, since one can part determinants into sender-specific effects, receiver-specific effects, and dyad-specific costs. With regard to Eq. (3), the estimated fixed effects correspond to 


$$
\begin{gathered}
\Lambda_{t}^{j}=\frac{1}{v} \beta V_{t+1}^{j}-\frac{1}{v} \beta V_{t+1}^{1} \\
\Gamma_{t}^{i}=\log \left(L_{t}^{i}\right)-\frac{1}{v}\left(\beta V_{t+1}^{i}+\Omega_{t}^{i}\right)+\frac{1}{v} \beta V_{t+1}^{1} \\
\Psi_{t}^{i j}=-\frac{1}{v} m_{t}^{i j}
\end{gathered}
$$

using $\Lambda_{t=1, \ldots, T}^{1}$ as reference category to ensure non-singularity of the matrix of explanatory variables. As in Anderson (2011), the mass of $i$, given by its labor force, is assumed to positively increase migration flows, while distance naturally is assumed to have negative impact. Further, flows from $i$ to $j$ are presumed higher the higher the expected net gains of $j$ compared to staying. $\Psi_{t}^{i j}$ is decomposed into three components, such that

$$
\Psi_{t}^{i j}=\alpha_{1, t} \mathbf{1}_{i \neq j}+\alpha_{2, t} \mathbf{1}_{s t a t e}+\alpha_{3, t} d^{i j}
$$

where $\mathbf{1}$ is the indicator function. Thus, migration costs are separated into fixed costs that arise by leaving the home region $\left(\mathbf{1}_{i \neq j}\right)$, leaving the home state $\left(\mathbf{1}_{\text {state }}\right)$, and into travel distance measured as the log of minutes it takes to travel from one regional central city to the other by car (see Table 4 in "Appendix" section), received from Google API. ${ }^{6}$ For movements within a region, $d^{i i}=0$ is assumed due to lack of information on these moves. Then, however, $\alpha_{1, t}$ can be interpreted as an estimate of average within resettling cost. As shown in the next section, it is possible to test whether the relevance of distance has declined over time, similar to what Poncet (2006) concludes for Chinese provinces.

In the recent discourse, a fair amount of effort has been spent on determining an adequate econometric approach to gravity equations. Bilateral data, may it capture trade flows or movements, generally has to deal with two complications. First, such data is frequently ripe with a significant amount of zero flows. Second, bilateral data prove to be heteroscedastic. Silva and Tenreyro (2006) show that if this heteroscedasticity depends on some covariates, estimation of a log-linear specification is inherently inconsistent since also the expected error is not independent of the covariates. Additionally, the manipulation of a relatively large share of zero flows for taking logarithms may create problems of its own. As a way out, Silva and Tenreyro (2006) propose using a pseudo Poisson maximum likelihood (PPML) estimator in levels, which is also supported by Beine et al. (2014), for example. Silva and Tenreyro $(2010,2011)$ additionally provide simulation evidence for the superiority of PPML in this context. The advantage of the PPML estimator compared to a linear approach is that the only condition for consistency is correct specification of the conditional expectation, which makes it particulary useful for bilateral data (Cameron and Trivedi 2013).

\footnotetext{
${ }^{6}$ Unfortunately, it is not possible to receive historic travel times, thus travel times are assumed timeinvariant. However, coefficients may change over time.
} 
That any flow from one location to another can be perturbed by shocks in some third location has long been recognized (Foot and Milne 1984, for example). Thus, in modelling migration flows, it is generally agreed upon that characteristics of alternative destinations need to be considered. Bertoli and Moraga (2013) argue that disregarding the attractiveness of other destinations causes endogeneity problems if the property of independence of irrelevant alternatives does not hold. Also, neglecting multilateral resistance may lead to biased estimates of origin-specific influences. Such influences, however, can be accounted for by using origin-year fixed effects, following Beine et al. (2014). Relating to these concerns raised by familiar gravity approaches, such considerations are accounted for by using sender-time and destination-time fixed effects, as depicted in Eq. (7).

The data at hand covers all bilateral movements, as opposed to many works that investigate one-way movements within a gravity-type framework, like Karemera et al. (2000), Mayda (2010) or Bertoli and Moraga (2013). The panel structure that is exploited allows an extensive fixed effects approach to account for unobserved, possibly correlated effects (Egger 2000). This means that choices of all agents within this system of regions are observed over time, which allows to infer efficiently on migration costs and regions' attractiveness levels.

In the second stage, Artuç (2013) suggests estimating the remaining choice-specific utility parameters with respect to some reference choice as

$$
\phi_{t}^{i}=\zeta_{t}+\eta_{1}^{i}+\eta_{2}^{i} t+\frac{\beta}{v} w_{t+1}^{i}+\xi_{t}^{2, i}
$$

with $v$ as the scale parameter of the distribution of the idiosyncratic utility shifters, in the following labelled 'taste', and the dependent variable constructed as

$$
\phi_{t}^{i}=\Lambda_{t}^{i}+\beta \Gamma_{t+1}^{i}-\log \left(L_{t+1}^{i}\right)
$$

Using this synthetic dependent variable, one can exploit the structural form in Eq. (3) to create moment conditions based on the first stage estimates. With the remaining fixed effects as explanatory variables, the second step allows to estimate the choice-specific time-invariant effects as well as the scale parameter. For the interested reader, Artuç (2013) provides a thorough derivation of the second stage. Note that in Eq. (12) the unobserved region-specific utility $\eta$ may follow a time trend. Obviously, movements of labor may affect the evolution of wages through shifts in labor supply or goods demand. Due to this endogeneity of $w_{t+1}^{i}$, an instrumental variable estimator is used. Thereby, contemporary wages serve as instruments for next period's wages, which also reflects the nature of workers' expectations about future developments by using today's information. ${ }^{7}$ Given the estimates of these two regressions, it is possible to construct valuations of all regions over time, the importance of the wage level as well as the idiosyncratic utility shocks, and the size of migration costs compared to the approximation of the wage level.

\footnotetext{
7 Given that $\phi_{t}^{i}$ contains $\Lambda_{t}^{i}$, next period's wages are endogenous, but contemporary wages $w_{t}^{i}$ are not, such that they can be used as instrument.
} 


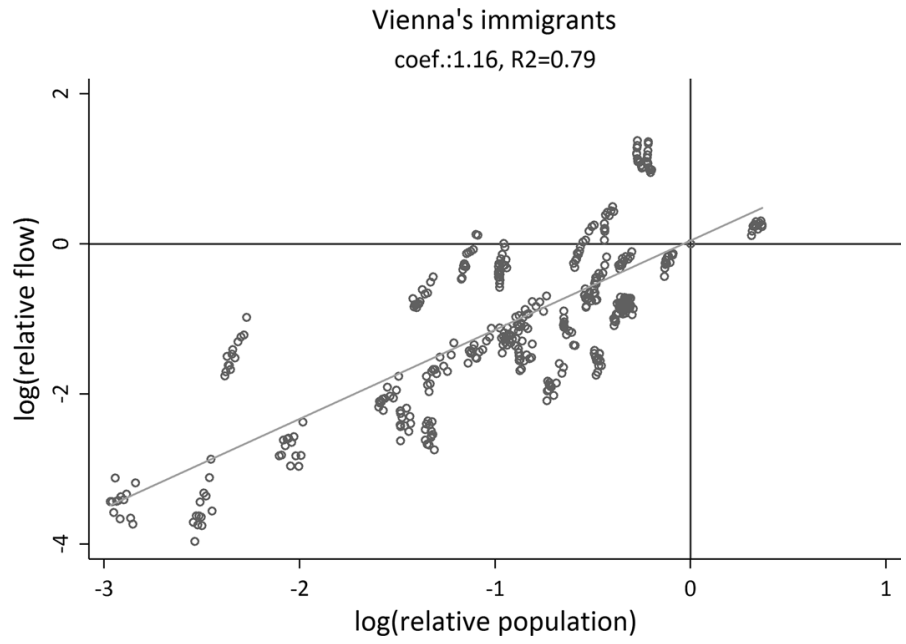

Fig. 3 Relative immigration to Vienna (without intra-Vienna flows) versus relative population, where Graz, the second largest city in Austria, builds the origin in both variables

\subsection{Data-Austrian internal migration}

Statistics Austria provides detailed data on internal migration flows, where the most fine-grain level is districts. However, since real GVA per employee and unemployment rates are available only at the NUTS 3 level and also to limit the possibility of mis-measurement, NUTS 3 regions are the preferred aggregation level. Austria contains 35 such regions, which are observed from 2002 to 2014, with a mean population of roughly 237,000 inhabitants $(195,000$ excluding Vienna), ranging from 20,676 to $1,770,049$. The sample comprises 15,925 flows, of which approximately $4 \%$ are nil. Also the variation in movements is large, in turn determined by the variation in the size of regions. For example, between 2002 and 2014, in only 5 years either one, two, or three persons moved from Weinviertel (AT125) to Außerfern (AT331). ${ }^{8}$ Taking a closer look at the data, it becomes evident that the typical implications of the gravity approach also fit small-scale regional migration flows. Leaning on Anderson (2011), Fig. 3 shows a log-linear relationship between relative migration flows and relative population of the sending region for immigration to Vienna. ${ }^{9}$ Further, Fig. 4 depicts the relationship between log migrations and the $\log$ road distance in 2005, and underlines the similarity of migratory flows to gravitational behavior.

Concerning the second stage estimation, the approximation of the expected wage is constructed using real GVA per employee and the unemployment rate. Thereby,

\footnotetext{
${ }^{8}$ In the other direction, there are also only five counts, ranging between two and five.

9 This point also extends to other regions and to emigration, which, for the sake of redundancy, are not shown here.
} 


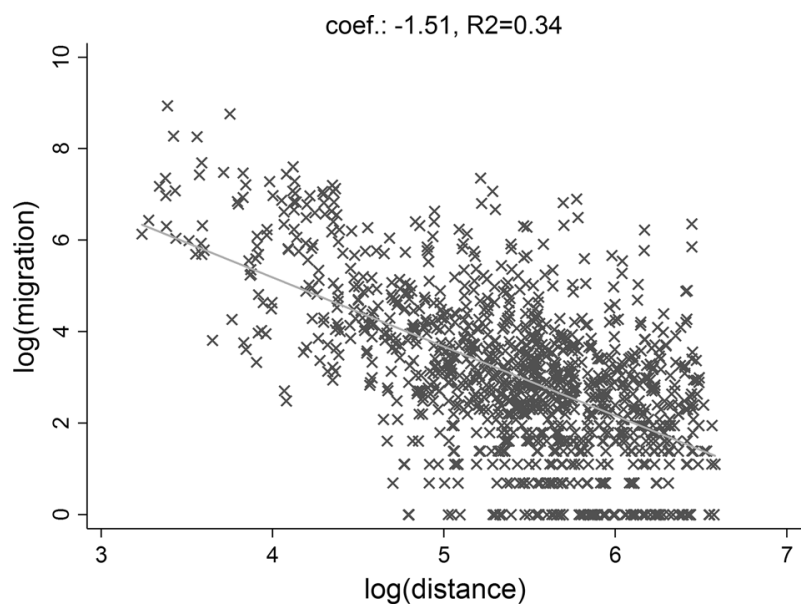

Fig. 4 Log migration flows versus log road distance between NUTS 3 central cities without intra-region movements, 2005

the real wage measure has a mean value over regions and time of $€ 47,555$ and a standard deviation of $€ 7222$. Spatially, larger values are concentrated in densely populated areas, with the highest values concentrated in and around Vienna and the regions between Salzburg and Linz, and in the vicinity of the Swiss border. For the unemployment rate, the mean value is at $6.56 \%$, with a standard deviation of $1.69 \%$. The spatial distribution in unemployment rates is smoother, with the lowest values in Upper Austria (AT31), and the highest values concentrated in the south of Austria and the capital region Vienna. Taken together, the expected real wage variable is calculated as gross value added per employee multiplied by one minus the unemployment rate. For the second stage estimation, this variable is normalized to unity in order to make estimated migration costs easily comparable, such that the variable represents the average relative real expected wage. Lastly, travel time is measured in minutes it takes to drive from one regional center to another by car, with a mean value of 173.80 and a standard deviation of $90.53 \mathrm{~min}$. See "Appendix" section for summary statistics in Table 4 and maps of the distribution of real wages and unemployment rates in Figs. 7 and 8.

\section{Results}

As indicated above, regional valuations, migration costs in comparison to the wage level, and the importance of idiosyncratic shocks in movers' choices can be reconstructed. Given the number of estimates, "Appendix" section summarizes some important results graphically. Note that for the second stage and regarding the valuation of a region, results are to be taken with respect to some reference. In this case, the reference is 'Außerfern' (AT331), a rural region in the west of Austria on the border to Germany with a relatively small population of 
Table 1 First and second stage regression results

\begin{tabular}{|c|c|c|c|c|}
\hline First stage PPML & Travel time (min) & Estimate & SE & Difference $(p)$ \\
\hline \multicolumn{5}{|l|}{2002 movings costs } \\
\hline \multicolumn{5}{|l|}{ Coefficients $\cdot(-1)$} \\
\hline Leaving region & & $-3.828 * * *$ & 0.381 & \\
\hline Crossing state border & & 0.082 & 0.136 & \\
\hline Travel time & & $1.877 * * *$ & 0.100 & \\
\hline \multicolumn{5}{|l|}{ Combined migration cost } \\
\hline 5 th percentile & 49.67 & $3.420 * * *$ & 0.106 & \\
\hline Mean & 148.9 & $5.481 * * *$ & 0.059 & \\
\hline 95th percentile & 352.4 & $7.100 * * *$ & 0.119 & \\
\hline \multicolumn{5}{|l|}{2014 moving costs } \\
\hline \multicolumn{5}{|l|}{ Coefficients $\cdot(-1)$} \\
\hline Leaving region & & $-3.534 * * *$ & 0.371 & 0.580 \\
\hline Crossing state border & & 0.072 & 0.122 & 0.400 \\
\hline Travel time & & $1.723 * * *$ & 0.097 & 0.266 \\
\hline \multicolumn{5}{|l|}{ Combined migration cost } \\
\hline 5th percentile & 49.67 & $3.266 * * *$ & 0.102 & 0.296 \\
\hline Mean & 148.9 & $5.158 * * *$ & 0.062 & 0.000 \\
\hline 95th percentile & 352.4 & $6.642 * * *$ & 0.121 & 0.007 \\
\hline \multicolumn{5}{|c|}{ Second stage IV estimation } \\
\hline $\begin{array}{l}\text { Expected wage } \\
\quad\left(\text { GVA/emp } \cdot\left(1-u_{i t}\right)\right)\end{array}$ & & $0.830^{* *}$ & 0.420 & \\
\hline$\tilde{v}(\beta$ assumed 0.95$)$ & & $1.149 * *$ & $0.051(p)$ & \\
\hline
\end{tabular}

Regression results: migration costs over time estimated by PPML in the first stage. Travel time is measured in $\log (\mathrm{min})$ from one regional central city to another. Column 'difference' tests estimates/estimated costs in 2002 with those in 2014. The estimator for $v$ follows from the second stage instrumental variable regression. $(p)$ indicates the $p$ value. Percentiles and the mean of travel time are taken conditional on a travel time greater than zero

$* * * p<0.01, * * p<0.05, * p<0.1$

approximately $20 \%$ of the median population, and a real expected wage around $20 \%$ above than the median.

\subsection{Migration costs and the importance of 'taste'}

As proposed in Artuç (2013), the two-step estimation approach allows to infer on the importance of the random utility shifter $\varepsilon$ by assuming a common discount factor $\beta .^{10}$ In doing so, the estimated value $\tilde{v}$ is at 1.149 , and given the distribution of this taste

\footnotetext{
${ }_{10}$ Throughout, the discount factor $\beta$ is assumed at 0.95 . Most commonly this factor varies between 0.9 and 0.97 , and results are hardly influenced by the exact choice. For a discount of 0.9 , the estimated $\tilde{\nu}$ is at 1.08 , and increases to 1.19 for a discount factor of 0.99 .
} 
shocks, the standard deviation is 1.47. Concerning the comparison of the current location and some alternative, the standard deviation of the combined moving costs, deterministic plus stochastic, follows the logistic distribution, amounting to a value of $2.08 .^{11}$

Figure 9 ("Appendix" section) shows two main points of the first stage PPML regression defined in Eq. (7). First, there is no indication that moving from one state ('Bundesland') to another incurs any additional costs. Due to the fact that the bulk of movements in Austria is either to or away from its capital Vienna, which is also a single region and state, this is not too surprising. Further, migration costs appear to have declined over time, given by the slight absolute decline of the coefficients of travel time and crossing the region border. Table 1 compares these costs in 2002 and 2014, and concludes that even though coefficients do not significantly change, estimated costs do.

The normalization of the wage variable and an estimate of $v$ allow measuring migration costs in terms of average annual real expected wages (Artuç and McLaren 2015). Recalling Eq. (6), multiplying the estimated migration costs by $\tilde{v}$ results in mean costs amounting to approximately 6.3 times the average expected annual real wage in 2002 and 5.9 times in 2014. For interregional movements, the estimates correspond to approximately 4.4 times the average expected annual real wage in 2002 and 4.0 times in 2014. This elicitation of regional migration costs lacks any reference to the best of the author's knowledge, but appears sizable. Thus, even if potential movers were sensitive to regional differentials in wages or unemployment, migration costs would prevent these differentials to be taken advantage of. ${ }^{12}$

The same argumentation holds for the variation in taste. According to the model outlined above, total migration costs, due to the taste shocks, follow a logistic distribution with an estimated standard deviation of approximately 2.1 times the average expected annual real wage.

In conclusion, even if regional differentials were a significant driver of migration, high migration costs would prevent alleviation. After all, it seems that random or at least non-economic tastes are more important determinants. These results further support investigations, for example Groenewold (1997) or Fidrmuc (2004), finding at most minor effects of migration on differentials in wages or unemployment.

\subsection{Valuation of regions and possible determinants}

The second stage estimation allows reconstructing the value function (3). Regionfixed as well as expected valuations, though, are to be seen with respect to the reference region. Figure 10 ("Appendix" section) summarizes estimates for $\tilde{\eta}_{1}^{i}$ and $\tilde{\eta}_{2}^{i} t$.

\footnotetext{
11 Using only the real gross value added per employee yields an estimated value of $\tilde{v}$ around unity.

12 As noted by a reviewer, one could calculate wage premiums to induce migration. A simple way would be within a search framework. In a simple set up, the relationship between home $\left(w^{i i}\right)$ and migrationinducing reservation wages $w^{i j}$ would be of the form $w^{i j}=w^{i i}+(1-\beta(1-\pi)) m^{i j}$, where $\pi$ is the breakup rate of any given job match. Inserting the estimated mean migration cost and assuming $\pi=0.075$ (and, importantly, no taste shock), one would end up at a migration premium of approximately half the expected gross value added per employee.
} 


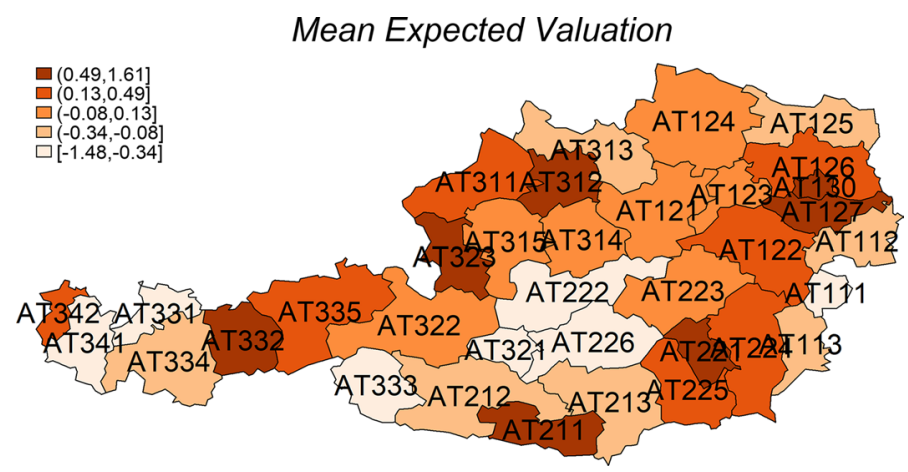

Fig. 5 Mean expected valuation of regions over the whole sample relative to the reference region (AT331)

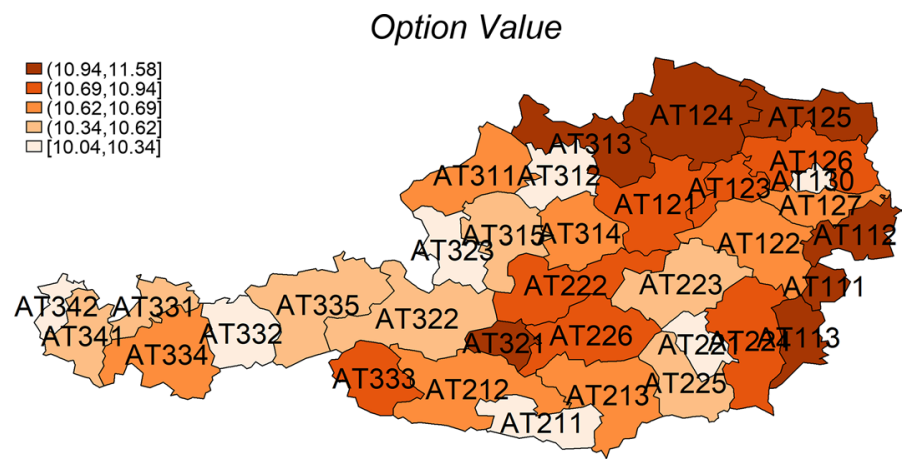

Fig. 6 Mean option values of regions over the whole sample

16 of the remaining 34 regions show significantly different fixed valuations with respect to the reference region. Further, there is a clear positive relationship between a region's population and expected valuations $\hat{\Lambda}_{t}^{i}$, which is investigated in more detail in the next subsection.

Combined with the observation that region-specific trend estimates do not seem to correlate with population, the conclusion is that the rural regions do not appear to catch up to denser populated areas in terms of attractiveness. As shown in Fig. 5, four out of the five highest valued regions are or contain a state capital city. ${ }^{13}$ Thus, conditional on expected wages, the trend to urbanization and suburbanization appears ongoing. With trend coefficients mostly not significantly different from one another, these differences in valuation appear persistent in the recent past.

Recalling Eq. (3), the remaining part of the value function is the predicted option value $\hat{\Omega}_{t}^{i}$. These valuations, created by the ease at which one could move to some other (higher) valued region, are concentrated in the east, in relative proximity to economic centers (see Fig. 6).

${ }_{13}$ The five regions in descending order are Vienna (AT130), Graz (AT221), Linz-Wels (AT312), Innsbruck (AT332), and Wiener Umland-Südteil (AT127). 
In fact, regions' (relative) expected valuations $\tilde{\Lambda}_{t+1}^{i}$ are negatively correlated with the corresponding option values, as equations (4) and (5) suggest. The yearwise correlations are in the range of -0.69 and -0.75 , which can also be observed by comparing Figs. 5 and 6. The interpretation is straightforward, in that this implies that by being in a high valued region, the chance to find a more attractive one is relatively smaller and vice versa.

\subsection{Possible (economic) determinants}

At last, the estimates allow inferring on potential economic determinants of a region's valuation over time. Considering the points made above, for small-scale areal units the intuition is that the locational decision of an individual may not only be determined by characteristics of the region itself, but also by characteristics of neighboring regions, where close-by ones would supposedly have a bigger influence, as Eq. (3) indicates. Using Eqs. (3) and (5), the model translates into a spatial-autoregressive type estimation. Since there may also be spatial dependence in unobserved factors, also the error structure is allowed to show spatial-autoregressive behavior. Thus, a spatial-autocorrelation (SAC) model is applied (LeSage and Pace 2008). The exact econometric specification is

$$
\begin{gathered}
\tilde{\boldsymbol{\Lambda}}_{t+1}=\rho \mathbf{W} \tilde{\boldsymbol{\Lambda}}_{t+1}+\mathbf{X}_{t} \boldsymbol{\gamma}+\boldsymbol{\eta}+\boldsymbol{\delta}+\boldsymbol{\epsilon}_{t} \\
\boldsymbol{\epsilon}_{t}=\lambda \mathbf{W} \boldsymbol{\epsilon}_{t}+\boldsymbol{u}_{t}
\end{gathered}
$$

where $\rho$ and $\lambda$, both smaller than unity in absolute value, measure spatial dependence in the dependent variable and the disturbances, $\gamma$ are coefficients of time-varying regressors, $\mathbf{X}_{t}$ is the set of time-varying exogenous variables, $\boldsymbol{\delta}$ and $\boldsymbol{\eta}$ capture time-fixed and region-fixed effects, and $\boldsymbol{\epsilon}_{t}$ and $\boldsymbol{u}_{t}$ represent spatially dependent and well-behaved disturbances. Concerning the spatial weights matrix $\mathbf{W}$, a full matrix is used, based on travel times that have already been introduced above. In this case, weights are calculated by

$$
w_{i j}=d_{i j}^{-\alpha}
$$

if $i \neq j$ and zero otherwise, and where $\alpha$ is an arbitrary positive constant. ${ }^{14}$ This specification fits well the intuition of the model, in which individuals may compare all possible alternatives in determining the value of region. In "Appendix" section, estimates based on contiguity-weights are presented. This would imply that a region's valuation is influenced by its direct neighbors, and only sequentially spreads through the system. Comparing these two cases allows examining how different presumed spatial processes affect the result. In both cases, the spatial weights matrices are row-normalized.

Given that expected valuations are estimates, there is innate uncertainty in the dependent variable. As a consequence, the estimator accounts for this uncertainty by weighting each region with the inverse standard error of $\tilde{\Lambda}_{t+1}^{i}$.

Explanatory variables are approximations of the relative economic well-being, structure, and the supply of amenities. Thereby, the choice of these variables is

$\overline{14}$ As calculations show, results are insensitive to different values of $\alpha$. 
Table 2 SAC estimation results

\begin{tabular}{|c|c|c|c|}
\hline & \multirow[t]{2}{*}{ Coefficient } & \multicolumn{2}{|c|}{ Estimated impact } \\
\hline & & Direct & Indirect \\
\hline Relative unemployment & $\begin{array}{l}-0.094 \\
(0.061)\end{array}$ & $\begin{array}{l}-0.093 \\
(0.063)\end{array}$ & $\begin{array}{l}0.021 \\
(0.015)\end{array}$ \\
\hline Relative GVA/worker & $\begin{array}{l}-0.448 \\
(0.297)\end{array}$ & $\begin{array}{l}-0.464 \\
(0.288)\end{array}$ & $\begin{array}{l}0.103 \\
(0.065)\end{array}$ \\
\hline Relative household exp. & $\begin{array}{l}0.583 \\
(0.453)\end{array}$ & $\begin{array}{l}0.617 \\
(0.441)\end{array}$ & $\begin{array}{l}-0.135 \\
(0.098)\end{array}$ \\
\hline Relative population density & $\begin{array}{l}0.241 * * * \\
(0.042)\end{array}$ & $\begin{array}{l}0.245 * * * \\
(0.043)\end{array}$ & $\begin{array}{l}-0.056^{* * *} \\
(0.016)\end{array}$ \\
\hline Manufacturing share & $\begin{array}{l}-0.144 \\
(0.575)\end{array}$ & $\begin{array}{l}-0.158 \\
(0.560)\end{array}$ & $\begin{array}{l}0.036 \\
(0.134)\end{array}$ \\
\hline Construction share & $\begin{array}{l}-0.979 \\
(0.941)\end{array}$ & $\begin{array}{l}-0.949 \\
(0.923)\end{array}$ & $\begin{array}{l}0.224 \\
(0.225)\end{array}$ \\
\hline Trade share & $\begin{array}{l}-0.104 \\
(0.781)\end{array}$ & $\begin{array}{l}-0.112 \\
(0.754)\end{array}$ & $\begin{array}{l}0.031 \\
(0.177)\end{array}$ \\
\hline Services share & $\begin{array}{l}0.149 \\
(1.010)\end{array}$ & $\begin{array}{l}0.138 \\
(0.979)\end{array}$ & $\begin{array}{l}-0.029 \\
(0.229)\end{array}$ \\
\hline Non-market services share & $\begin{array}{l}0.214 \\
(1.069)\end{array}$ & $\begin{array}{l}0.307 \\
(1.046)\end{array}$ & $\begin{array}{l}-0.060 \\
(0.225)\end{array}$ \\
\hline$\rho$ & $\begin{array}{l}-0.290 * * * \\
(0.083)\end{array}$ & & \\
\hline$\lambda$ & $\begin{array}{l}0.274 * * * \\
(0.100)\end{array}$ & & \\
\hline $\mathrm{R}^{2}$ & 0.690 & & \\
\hline Observations & 420 & & \\
\hline
\end{tabular}

Dependent variable is the estimated expected valuation from first stage PPML estimation. Observations weighted with region-wise inverse standard errors. Spatial weights based on travel time in minutes from one regional center to another. Weight matrix row-normalized. Direct, indirect, and total impacts are based on $(\mathbf{I}-\rho \mathbf{W})^{-1} \mathbf{X}_{t} \boldsymbol{\gamma}$ (LeSage and Pace 2008). Region- and time-fixed effects included. Standard errors in parentheses below $(* * * p<0.01, * * p<0.05, * p<0.1)$

limited in two rather common ways. The first is data-limitations concerning timevariant variables. Second, it is easy think of many time-invariant, or at least very slow-changing, factors that affect a region's appeal, like environmental amenities such as mountains, coastal areas or national parks, air quality, or land use in general (Waltert and Schläpfer 2010, for example). The supply of cultural amenities may also be highly consistent over time, for example opera houses, concert halls, or the overall (historic) cultural appeal of a city or region. The same holds for the presence of universities. These covariates, though, are then to fully captured in $\eta_{i}$.

Economic variables that enter $\mathbf{X}_{t}$ are relative unemployment rates, relative gross value added per employee as an approximation of the productivity, and sectorwise employment 
shares as a measure of industry structure. Thereby, the sectors are defined as manufacturing, construction, trade, services, and non-market services. ${ }^{15}$ Further, relative population density and relative household expenditure per capita enter as approximations of amenities. Table 4 in "Appendix" section presents summary statistics of all variables.

Estimation results based on the full spatial weights matrix, shown in Table 2, offer some interesting conclusions. First, relative unemployment rates do not show significant impacts on expected valuations. Given that valuations in turn trigger migration, the conjecture is that unemployment is not a significant driver of migration on a small-scale regional level. This conjecture is in line with strands of the literature that investigate the relationship between migration and regional unemployment (Etzo 2008, for a review). Further, no other direct economic determinants, gross value added per employee and sector shares, show significant impacts. Only the coefficient of (relative) population density is significantly positive, expressing higher supply of amenities in denser areas. Even though gross value added per employee and population density are positively correlated to a high degree, directs impacts of the former cannot be supported. ${ }^{16}$

The most important result in Table 2 is revealed by the estimated spatial parameters and the implied direct and indirect impacts. First, the estimated value of $\lambda$ shows that unobserved influences are highly spatially dependent and spread through the system, which can be expected given the small size of the areal units. Second, the negative estimate of $\rho$ implies that regions can be viewed as being negatively influenced by a neighboring region's appeal. This can explain patterns of central and surrounding less important, peripheral regions, as Fig. 5 would suggest. After all, this result indicates that regions can be thought of being in a beauty contest. There, being close to a strong 'competitor' tends to make a weaker competitor look ever weaker.

\section{Conclusion}

The motivation for this paper is the notion that regional migration appears to show little response to regional differentials in economic determinants despite its seemingly, at least in theory, enormous potential to react, and even alleviate those differentials. By using a dynamic discrete choice set up proposed by Artuç (2013), investigating recent Austrian bilateral migration flows from 2002 to 2014 reveals two main results which - partly — constitute migration's inability to alleviate regional differentials.

First, results show that mean migration costs are in the range of 5.9 times the average expected gross value added per employee in 2014. This value appears sizable enough to allow regional differentials to persist, as the potential gains from migration that would even out these differentials have large threshold to induce migration. On the contrary, high migration costs may cause increasing differentials by allowing only the most capable to migrate, those who face the highest expected gains, potentially leading to a brain drain scenario (Dotti et al. 2013, for example). Still, these costs are shown to have significantly decreased over time. The main follow-up questions are whether these seemingly immense costs are an Austrian idiosyncrasy, and what these costs consist of.

\footnotetext{
15 The agricultural sector is dropped to avoid perfect collinearity in $\mathbf{X}_{t}$.

16 The correlation between (relative) real GVA per employee and (relative) population density is around 0.4.
} 
Given that there may be numerous determinants of migration costs conditional on an individuals' characteristics like age, education, employment, occupation, or family ties, using more fine-grain level data could shed light on this question.

The second possible explanation why workers may seem unresponsive to economic incentives besides high migration costs is that, in fact, they may just not be that concerned with economic opportunities in making locational decisions. This is shown by the relatively high estimates of the variation of the random utility/cost shifter, which may be seen in stark contrast to what studies on international migration typically find (McKenzie et al. 2014; Mayda 2010). The estimated standard deviation of the choice-specific random components of around 2.1 times the average real expected GVA per employee demonstrate that non-economic determinants tend to be highly important for the valuation of regions.

Concerning the revealed valuation of regions, the estimates advocate that the difference between (higher valued) urban and intermediate regions and the (lower valued) rural regions appears persistent such that the trend to (sub-)urbanization is ongoing. Based on estimated expected valuations, a weighted spatial-autocorrelation estimator stresses the insignificance of relative unemployment rates and wages as determinants of valuation, and in extension aggregate regional migration patterns. As a centerpiece, the spatial parameters expose the interdependence of neighboring regions. Unobserved shocks in valuations are highly spatially correlated, such that they spread swiftly to close-by regions. An intuitive example for such spatiallydependent shocks are natural disasters such as floods. Lastly, the negative estimate of the spatial autoregressive parameter implies that regions appear in competition about potential immigrants. Figuratively speaking, if the grass on the other side of the fence is greener, it lets one's own seem ever paler.

At the end, it appears that the decision to relocate may be driven to a larger extent by other factors, and economic determinants may only play a secondary role. Again, the question is whether and, if so, to what extent these results are idiosyncratic for the Austrian case. There are at least two explanations that point in this direction. First, Austria has a relatively high level of social security, which might impair the willingness to migrate. According to the OECD, Austria ranked sixth in social expenditures as share of the gross domestic product in 2016 and fourth in expenditures per capita (in 2013). ${ }^{17}$ Second, the relatively high willingness to commute and the fact that it is subsidized may be a reason for a relative unwillingness to migrate. Relating to the theory applied in this study, the ease of commuting may shift valuations of otherwise unfavorable regions upwards, leaving migrating relatively less profitable. After all, in 2015, more than one half of employees residing in Austria did not work in their home municipality, of those approximately $21 \%$ worked in another district within the same state, and about $13 \%$ in another state or abroad. ${ }^{18}$

Acknowledgements Open access funding provided by Johannes Kepler University Linz. The author would like to thank the participants of the 10th Geoffrey J.D. Hewings Regional Economics Workshop/10th Summer Conference in Regional Science at the Austrian Institute of Economic Research, Vienna, in 2017. In

\footnotetext{
17 See http://www.stats.oecd.org.

18 See http://www.statistik.at.
} 
particular, Michael Pfaffermayr, Jesus Crespo-Cuaresma, Peter Huber, and Harald Oberhofer deserve gratitude for valuable discussions and comments. The author further thanks two anonymous referees.

Open Access This article is distributed under the terms of the Creative Commons Attribution 4.0 International License (http://creativecommons.org/licenses/by/4.0/), which permits unrestricted use, distribution, and reproduction in any medium, provided you give appropriate credit to the original author(s) and the source, provide a link to the Creative Commons license, and indicate if changes were made.

\section{Appendix: Summary statistics and additional tables}

See Tables 3, 4, 5 and Figs. 7, 8, 9, 10.

Table 3 SAC estimation results, contiguity

\begin{tabular}{|c|c|c|c|c|}
\hline & \multirow[t]{2}{*}{ LSDV } & \multirow[t]{2}{*}{ Coefficient } & \multicolumn{2}{|c|}{ Estimated impact } \\
\hline & & & Direct & Indirect \\
\hline Relative unemployment & $\begin{array}{l}-0.128 * * \\
(0.052)\end{array}$ & $\begin{array}{l}-0.061 \\
(0.061)\end{array}$ & $\begin{array}{l}-0.066 \\
(0.071)\end{array}$ & $\begin{array}{l}0.031 \\
(0.034)\end{array}$ \\
\hline Relative GVA/worker & $\begin{array}{l}-0.514^{*} \\
(0.298)\end{array}$ & $\begin{array}{l}-0.410^{*} \\
(0.243)\end{array}$ & $\begin{array}{l}-0.477 * \\
(0.264)\end{array}$ & $\begin{array}{l}0.228 * \\
(0.132)\end{array}$ \\
\hline Relative household exp. & $\begin{array}{l}0.541 \\
(0.509)\end{array}$ & $\begin{array}{l}0.618^{*} \\
(0.365)\end{array}$ & $\begin{array}{l}0.728^{*} \\
(0.398)\end{array}$ & $\begin{array}{l}-0.348 * \\
(0.199)\end{array}$ \\
\hline Relative population density & $\begin{array}{l}0.223 * * * \\
(0.052)\end{array}$ & $\begin{array}{l}0.249 * * * \\
(0.037)\end{array}$ & $\begin{array}{l}0.285 * * * \\
(0.040)\end{array}$ & $\begin{array}{l}-0.138 * * * \\
(0.030)\end{array}$ \\
\hline Manufacturing share & $\begin{array}{l}0.401 \\
(0.584)\end{array}$ & $\begin{array}{l}-0.529 \\
(0.558)\end{array}$ & $\begin{array}{l}-0.606 \\
(0.617)\end{array}$ & $\begin{array}{l}0.290 \\
(0.311)\end{array}$ \\
\hline Construction share & $\begin{array}{l}-0.495 \\
(1.019)\end{array}$ & $\begin{array}{l}-0.853 \\
(0.833)\end{array}$ & $\begin{array}{l}-0.933 \\
(0.923)\end{array}$ & $\begin{array}{l}0.454 \\
(0.465)\end{array}$ \\
\hline Trade share & $\begin{array}{l}0.249 \\
(0.764)\end{array}$ & $\begin{array}{l}-0.269 \\
(0.753)\end{array}$ & $\begin{array}{l}-0.306 \\
(0.827)\end{array}$ & $\begin{array}{l}(0.140) \\
(0.414)\end{array}$ \\
\hline Services share & $\begin{array}{l}0.710 \\
(0.997)\end{array}$ & $\begin{array}{l}-0.396 \\
(1.035)\end{array}$ & $\begin{array}{l}-0.440 \\
(1.132)\end{array}$ & $\begin{array}{l}0.199 \\
(0.562)\end{array}$ \\
\hline Non-market services share & $\begin{array}{l}0.557 \\
(1.141)\end{array}$ & $\begin{array}{l}-0.169 \\
(0.948)\end{array}$ & $\begin{array}{l}-0.125 \\
(1.052)\end{array}$ & $\begin{array}{l}0.055 \\
(0.534)\end{array}$ \\
\hline$\rho$ & & $\begin{array}{l}-0.703 * * * \\
(0.141)\end{array}$ & & \\
\hline$\lambda$ & & $\begin{array}{l}0.752 * * * \\
(0.087)\end{array}$ & & \\
\hline $\mathrm{R}^{2}$ & & 0.681 & & \\
\hline Mean of fixed effect & & 1.367 & & \\
\hline Observations & 420 & 420 & & \\
\hline
\end{tabular}

Dependent variable is the estimated expected valuation from first stage PPML estimation. Observations weighted with region-wise inverse standard errors. Column 'LSDV' presents least squares dummy variables estimation results without spatial interaction. Spatial weights based on travel time in minutes from one regional center to another. Weight matrices are row-normalized. Direct, indirect, and total impacts are based on $(\mathbf{I}-\rho \mathbf{W})^{-1} \mathbf{X}_{t} \boldsymbol{\gamma}$ (LeSage and Pace 2008). Standard errors in parentheses below $(* * * p<0.01, * * p<0.05, * p<0.1)$ 
Table 4 Summary statistics

\begin{tabular}{|c|c|c|c|c|c|c|c|}
\hline Variable & $\mathrm{n}$ & Min & p5 & Median & Mean & p95 & $\operatorname{Max}$ \\
\hline Migration flow & 15,925 & 0.00 & 1.00 & 21.00 & 557.88 & 1101.00 & $158,010.00$ \\
\hline Travel time (min) & 1225 & 0.00 & 38.10 & 156.50 & 168.84 & 351.08 & 417.68 \\
\hline GVA per employee & 455 & $34,177.14$ & $38,260.32$ & $47,555.37$ & $48,169.05$ & $61,870.48$ & $70,431.23$ \\
\hline Real expected wage & 455 & $31,203.73$ & $35,215.63$ & $44,268.86$ & $45,018.62$ & $57,022.75$ & $66,329.02$ \\
\hline Unemployment rate & 455 & 3.02 & 4.08 & 6.45 & 6.56 & 9.72 & 13.40 \\
\hline \multicolumn{8}{|l|}{ Relative variables } \\
\hline Unemployment rate & 420 & 0.51 & 0.66 & 0.98 & 1.00 & 1.47 & 1.76 \\
\hline GVA per employee & 420 & 0.77 & 0.79 & 0.99 & 1.00 & 1.27 & 1.34 \\
\hline Household exp. p.c. & 420 & 0.83 & 0.87 & 0.99 & 1.00 & 1.17 & 1.26 \\
\hline Population density & 420 & 0.09 & 0.12 & 0.34 & 1.00 & 1.81 & 19.52 \\
\hline \multicolumn{8}{|l|}{ Employment shares } \\
\hline Manufacturing & 420 & 0.08 & 0.09 & 0.18 & 0.19 & 0.29 & 0.33 \\
\hline Construction & 420 & 0.05 & 0.05 & 0.07 & 0.08 & 0.11 & 0.14 \\
\hline Trade & 420 & 0.20 & 0.22 & 0.26 & 0.28 & 0.41 & 0.43 \\
\hline Service & 420 & 0.05 & 0.06 & 0.09 & 0.10 & 0.19 & 0.26 \\
\hline Non-market service & 420 & 0.16 & 0.18 & 0.24 & 0.25 & 0.34 & 0.36 \\
\hline
\end{tabular}


Table 5 Regions and regional centers for the calculation of road distances

\begin{tabular}{|c|c|c|c|}
\hline NUTS & Region name & Central city & \\
\hline AT111 & Rural, close to city & Mittelburgenland & Oberpullendorf \\
\hline AT112 & Rural, close to city & Nordburgenland & Eisenstadt \\
\hline AT113 & Rural, close to city & Suedburgenland & Oberwart \\
\hline AT121 & Rural, close to city & Mostviertel-Eisenwurzen & Amstetten \\
\hline AT122 & Intermediate, close to city & Niederoesterreich-Sued & Wiener Neustadt \\
\hline AT123 & Rural, close to city & ST. Poelten & St. Poelten \\
\hline AT124 & Rural, remote & Waldviertel & Krems an der Donau \\
\hline AT125 & Rural, close to city & Weinviertel & Hollabrunn \\
\hline AT126 & Urban & Wiener Umland Nordteil & Stockerau \\
\hline AT127 & Urban & Wiener Umland Suedteil & Baden \\
\hline AT130 & Urban & Wien & Wien \\
\hline AT211 & Intermediate, close to city & Klagenfurt Villach & Klagenfurt \\
\hline AT212 & Rural, remote & OberkÃărnten & Spittal an der Drau \\
\hline AT213 & Rural, close to city & UnterkÃarnten & Wolfsberg \\
\hline AT221 & Intermediate, close to city & Graz & Graz \\
\hline AT222 & Rural, remote & Liezen & Liezen \\
\hline AT223 & Intermediate, close to city & oestliche Obersteiermark & Leoben \\
\hline AT224 & Rural, close to city & Oststeiermark & Gleisdorf \\
\hline AT225 & Rural, close to city & West/Suedsteiermark & Deutschlandsberg \\
\hline AT226 & Rural, remote & Westliche Obersteiermark & Judenburg \\
\hline AT311 & Rural, close to city & Innviertel & Ried im Innkreis \\
\hline AT312 & Intermediate, close to city & Linz-Wels & $\operatorname{Linz}$ \\
\hline AT313 & Rural, close to city & Muehlviertel & Freistadt \\
\hline AT314 & Rural, close to city & Steyr-Kirchdorf & Steyr \\
\hline AT315 & Intermediate, close to city & Traunviertel & Gmunden \\
\hline AT321 & Rural, remote & Lungau & Tamsweg \\
\hline AT322 & Rural, remote & Pinzgau-Pongau & St. Johann im Pongau \\
\hline AT323 & Intermediate, close to city & Salzburg und Umgebung & Salzburg \\
\hline AT331 & Rural, close to city & AuÃ ̈̈erfern & Reutte \\
\hline AT332 & Urban & Innsbruck & Innsbruck \\
\hline AT333 & Rural, remote & Osttirol & Lienz \\
\hline AT334 & Rural, remote & Oberland & Imst \\
\hline AT335 & Rural, close to city & Unterland & Woergl \\
\hline AT341 & Rural, close to city & Bludenz/ Bregenzer Wald & Bludenz \\
\hline AT342 & Urban & Rheintal/Bodensee & Dornbirn \\
\hline
\end{tabular}




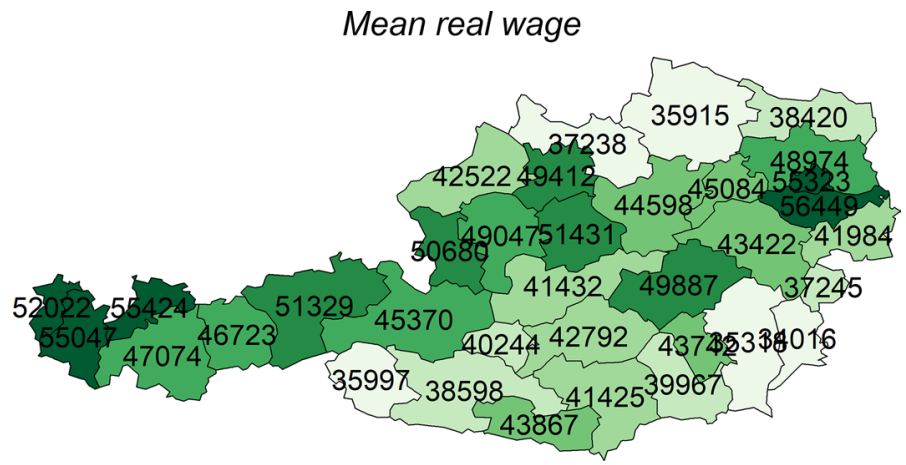

Fig. 7 Mean real wage (gross value added per employee) between 2002 and 2014 calculated as real gross value added per employee

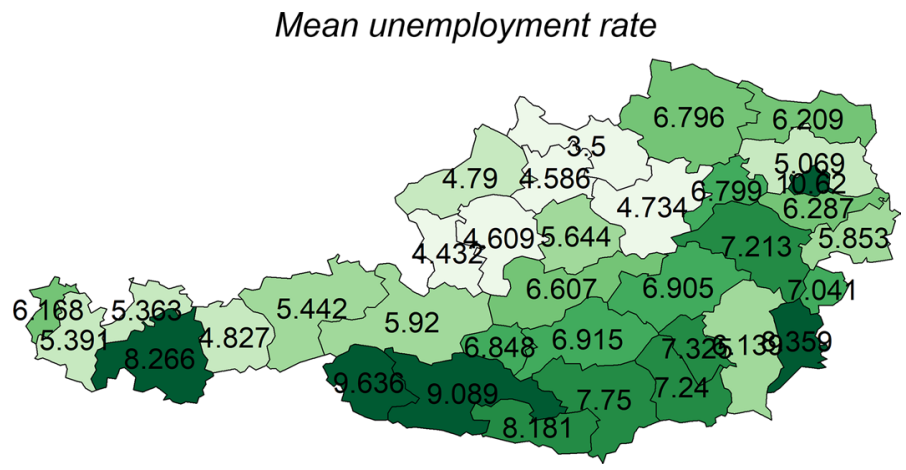

Fig. 8 Mean unemployment rate between 2002 and 2014

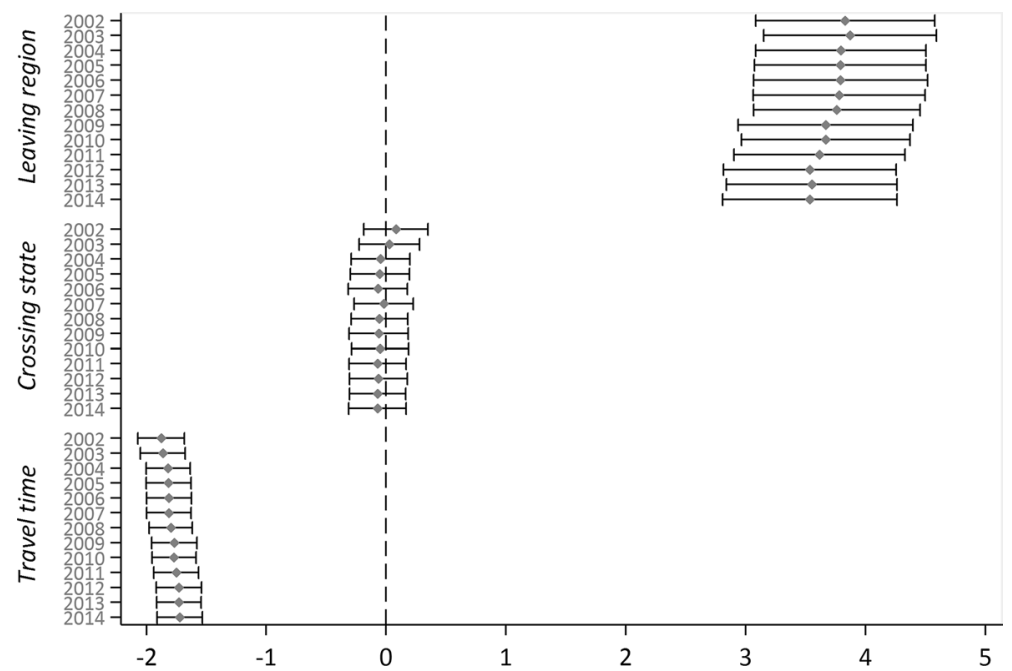

Fig. 9 Estimated coefficients of migration costs over time-point estimates with 95\% confidence intervals using PPML 


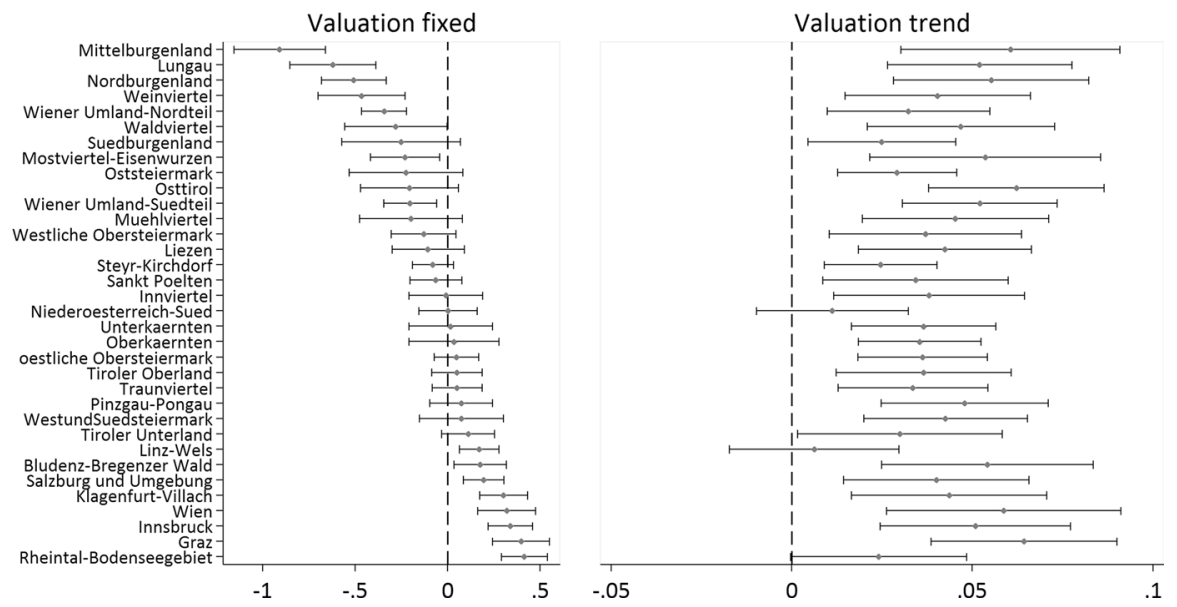

Fig. 10 Second stage estimation-region-specific fixed valuation and time trend $\tilde{\eta}_{1}^{i}+\tilde{\eta}_{2}^{i} t$ with corresponding confidence intervals, sorted by fixed valuation with respect to the reference region AT331

\section{References}

Anderson JE (2011) The gravity model. Ann Rev Econ 3(1):133-160

Artuç E (2013) PPML estimation of dynamic discrete choice models with aggregate shocks. World Bank Policy Research Working Paper (No. 6480)

Artuç E, McLaren J (2015) Trade policy and wage inequality: a structural analysis with occupational and sectoral mobility. J Int Econ 97(2):278-294

Artuç E, Chaudhuri S, Mclaren J (2010) Trade shocks and labor adjustment: a structural empirical approach. Am Econ Rev 100(3):1008-1045

Barro RJ, Sala-i Martin X (1992) Regional growth and migration: a Japan-United States comparison. J Jpn Int Econ 6(4):312-346

Basile R, Girardi A, Mantuano M (2012) Migration and regional unemployment in Italy. Open Urban Stud J 5:1-13

Basile R, Girardi A, Mantuano M, Russo G (2016) Interregional migration, human capital externalities and unemployment dynamics: evidence from Italian provinces. Technical report, Centre for Studies in Economics and Finance (CSEF), University of Naples, Italy

Beine M, Parsons C (2015) Climatic factors as determinants of international migration. Scand J Econ 117(2):723-767

Beine M, Bertoli S, Moraga JF-H (2014) A practitioners' guide to gravity models of international migration. Doc Trabajo (FEDEA) 3:1-27

Bertoli S, Moraga JF-H (2013) Visa policies, networks and the cliff at the border. Etudes et Documents, n 27, CERDI

Bertoli S, Moraga JF-H, Ortega F (2013) Crossing the border: self-selection, earnings and individual migration decisions. J Dev Econ 101:75-91

Borjas GJ (2001) Does immigration grease the wheels of the labor market? Brook Pap Econ Act 2001(1):69-133

Borjas GJ (2003) The labor demand curve is downward sloping: reexamining the impact of immigration on the labor market. Q J Econ 118(4):1335-1374

Cameron AC, Trivedi PK (2013) Regression analysis of count data, vol 53. Cambridge University Press, Cambridge

Dijkstra L, Gáková Z (2008) Labour mobility between the regions of the EU-27 and a comparison with the USA. EU

Dotti NF, Fratesi U, Lenzi C, Percoco M (2013) Local labour markets and the interregional mobility of Italian university students. Spat Econ Anal 8(4):443-468 
Dustmann C, Glitz A, Frattini T (2008) The labour market impact of immigration. Oxf Rev Econ Policy 24(3):477-494

Egger P (2000) A note on the proper econometric specification of the gravity equation. Econ Lett 66(1):25-31

Etzo I (2008) Internal migration: a review of the literature. University Library of Munich, Germany

Fidrmuc J (2004) Migration and regional adjustment to asymmetric shocks in transition economies. J Comp Econ 32(2):230-247

Fischer LB, Pfaffermayr M (2017) The more the merrier? Migration and convergence among European regions. Reg Sci Urban Econ (forthcoming)

Foot DK, Milne WJ (1984) Net migration estimation in an extended, multiregional gravity model. J Reg Sci 24(1):119-133

Fratesi U, Riggi MR (2007) Does migration reduce regional disparities? The role of skill-selective flows. Rev Urban Reg Dev Stud 19(1):78-102

Granato N, Haas A, Hamann S, Niebuhr A (2015) The impact of skill-specific migration on regional unemployment disparities in Germany. J Reg Sci 55(4):513-539

Groenewold N (1997) Does migration equalise regional unemployment rates? Evidence from Australia. Pap Reg Sci 76(1):1-20

Jackman R, Savouri S (1992) Regional migration in Britain: an analysis of gross flows using NHS central register data. Econ J 102(415):1433-1450

Karemera D, Oguledo VI, Davis B (2000) A gravity model analysis of international migration to North America. Appl Econ 32(13):1745-1755

Kırdar MG, Saracoğlu DŞ (2008) Migration and regional convergence: an empirical investigation for Turkey. Pap Reg Sci 87(4):545-566

Leblang DA, Fitzgerald J, Teets J (2009) Defying the law of gravity: the political economy of international migration. Available at SSRN 1421326

LeSage J, Pace RK (2008) Introduction to spatial econometrics. CRC Press, Boca Raton

Mayda AM (2010) International migration: a panel data analysis of the determinants of bilateral flows. J Popul Econ 23(4):1249-1274

McFadden D (1974) Analysis of qualitative choice behavior. In: Zarmbdka P (ed) Frontiers in econometrics. Academic Press, New York

McKenzie D, Theoharides C, Yang D (2014) Distortions in the international migrant labor market: evidence from Filipino migration and wage responses to destination country economic shocks. Am Econ J Appl Econ 6(2):49-75

Niebuhr A, Granato N, Haas A, Hamann S (2012) Does labour mobility reduce disparities between regional labour markets in Germany? Reg Stud 46(7):841-858

Okkerse L (2008) How to measure labour market effects of immigration: a review. J Econ Surv 22(1):1-30

Piras R (2017) A long-run analysis of push and pull factors of internal migration in Italy. Estimation of a gravity model with human capital using homogeneous and heterogeneous approaches. Pap Reg Sci 96(3):571-602

Poncet S (2006) Provincial migration dynamics in China: borders, costs and economic motivations. Reg Sci Urban Econ 36(3):385-398

Ramos R, Surinach J (2013) A gravity model of migration between ENC and EU. IZA Discussion Paper, 7700

Samuelson PA (1948) International trade and the equalisation of factor prices. Econ J 58(230):163-184

Silva JAMCS, Tenreyro S (2006) The log of gravity. Rev Econ Stat 88(4):641-658

Silva JAMCS, Tenreyro S (2010) On the existence of the maximum likelihood estimates in Poisson regression. Econ Lett 107(2):310-312

Silva JAMCS, Tenreyro S (2011) Further simulation evidence on the performance of the Poisson pseudomaximum likelihood estimator. Econ Lett 112(2):220-222

Waltert F, Schläpfer F (2010) Landscape amenities and local development: a review of migration, regional economic and hedonic pricing studies. Ecol Econ 70(2):141-152 